\title{
A Comparative Field-Scale Simulation Study on Feasibility of SAGD and ES-SAGD Processes in Naturally Fractured Bitumen Reservoirs
}

\author{
Yaser Souraki ${ }^{1}$, Mohammad Ashrafi ${ }^{1} \&$ Ole Torsaeter ${ }^{1}$ \\ ${ }^{1}$ Department of Petroleum Engineering and Applied Geophysics, Norwegian University of Science and \\ Technology - NTNU, Trondheim, Norway \\ Correspondence: Yaser Souraki, Department of Petroleum Engineering and Applied Geophysics, Norwegian \\ University of Science and Technology - NTNU, S. P. Andersens vei 15A, Trondheim 7491, Norway. Tel: \\ 47-7359-4826. E-mail: yaser.souraki@ntnu.no
}

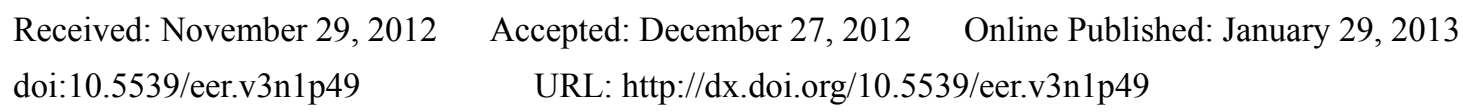

\begin{abstract}
Thermal processes are widely applied in heavy oil and bitumen reservoirs. Steam-Assisted Gravity Drainage (SAGD) and Expanding Solvent-SAGD (ES-SAGD) are the two most promising techniques for production of heavy oil and bitumen reservoirs. The feasibility and efficiency of the aforementioned processes have been studied extensively for sandstone reservoirs. As there are some naturally fractured heavy oil resources in the world similar thorough studies are necessary to find out the applicability of these processes in these types of reservoirs. In this work several numerical simulations have been performed to investigate the feasibility of these methods in naturally fractured reservoirs (NFR). Dual permeability option was applied in this study. This work tries to cover the effect of several parameters such as reservoir thickness, fracture permeability, matrix permeability, fracture spacing, steam quality and oil viscosity on SAGD and ES-SAGD processes. Results have elucidated that basically both methods are efficient and economically applicable in naturally fractured reservoirs. Recovery factor and cumulative steam-oil ratio (CSOR) were economical parameters to evaluate the performance of processes. However, in some cases net amount of injected energy and oil production rate were considered for evaluation too. Generally ES-SAGD had better performance based on the recovery factor, CSOR, oil production rate and net amount of injected energy. Effect of solvent type and concentration were studied for ES-SAGD process only. For this purpose, pentane, hexane and heptane were selected. Pentane displayed better performance in earlier periods of production; however the heavier solvents showed better recovery performance at later times.
\end{abstract}

Keywords: naturally fractured reservoirs, SAGD, ES-SAGD, heavy oil and bitumen

\section{Nomenclature}

Symbols

CSOR

ES-SAGD

GHG

$k_{r}$

NFR

$S_{w}$

SAGD

SAS

STB

VAPEX

THAI

CSS scripts

Cumulative Steam-Oil Ratio

Expanding Solvent-SAGD

Green-House-Gas

Relative Permeability

Naturally Fractured Reservoir

Water Saturation

Steam-Assisted Gravity Drainage

Steam-Alternating-Solvent

Stock Tank Barrel

Vapor Extraction

Toe-to-Heal Air Injection

Cyclic Steam Stimulation $g$ Gas

$o \quad$ Oil

$w \quad$ Water 


\section{Introduction}

Fractured reservoirs have complex structures, and are usually modeled based on dual porosity or dual permeability assumption. Production from fractured heavy oil reservoirs was not interesting for companies until a decade or so ago. Generally, researchers believed that high permeability of fractures provides an easy path for steam to bypass the oil without recovering significant amount of oil. However, results of several experimental works, simulation studies and some pilot tests in recent years indicated that thermal processes such as SAGD, Vapor Extraction (VAPEX) and hot-solvent injection are operationally feasible and economically efficient.

The fractures in reservoirs may have either negative or positive effects on flow of fluids inside the porous media (Aguilera, 1995). Naturally fractured reservoirs contain a remarkable portion (about one-third) of world-wide heavy oil and bitumen resources (Mollaie, 2010). Dusseault and Shafiei (2010) estimated around 2 trillion barrels of heavy oil to be deposited in carbonate fractured reservoirs. Canada, former Soviet Union and the Middle East have several fractured viscous oil reservoirs. The Alberta State of Canada has one of the largest carbonate bitumen resources which is contained in Grosmont formation and located in north-central Alberta. Among the several operated pilots on this formation, Cyclic Steam Stimulation (CSS) was the most prosperous method based on the recovery and CSOR (Edmunds et al., 2009). The estimated amount of Iranian heavy oil deposited in fractured reservoirs is about 86 billion STB (Kharrat et al., 2003).

To study the effect of fracture orientation towards well configurations on the SAGD process some experimental works have been done by Joshi (1986). The obtained data indicated that existence of vertical fractures perpendicular to the horizontal injector plane enable a fluent and clear path for steam to go upward resulting in high production of oil at earlier period of production. Pooladi-Darvish et al. $(1994,1995)$ analytically presented that in NFRs, heat conduction under gravity drainage is the primary heating mechanism. Azin et al. (2005) investigated feasibility of Vapor Extraction (VAPEX) method to Kuh-e-Mond field which is an Iranian heavy oil resource. They modeled the VAPEX process mathematically and to approve it they tried to history match the Butler and Jiang (2000) experimental data. Finally, they found good match and consistency between simulation results and experimental data. This model was applied to a fractured reservoir to study the effect of reservoir permeability, oil viscosity and solvent injection rate. They concluded that initial viscosity of oil affected the VAPEX process in fractured reservoirs. Also oil production rate increased with increase in matrix permeability.

Rostami et al. (2005) performed simulation study to evaluate the applicability of VAPEX process in high-pressure fractured heavy oil reservoirs. Results showed that optimum solvent injection rate should be found from economical and technical points of view. They investigated the effect of diffusion coefficient in fractured and non-fractured reservoirs and deduced that the amount of diffused solvent into the heavy oil was greater in a fractured system compared to a non-fractured system. Bagci (2006) has also performed several experiments to investigate the effect of fracture orientations towards well configurations on SAGD process. He found that performance of SAGD process was affected by location of fractures. Horizontal well pairs displayed the highest oil production in presence of fractures. He also deduced that SAGD performance was improved by vertical fractures.

3-D field scale SAGD simulation studies have been applied to one of Iran's viscous oil carbonate reservoirs by Sedaee Sola (2006). Results of simulation elucidated that SAGD is an efficient method for producing oil from this reservoir. Simulation analysis on the effect of vertical well spacing showed that the optimum vertical distance between wells should be $200 \mathrm{ft}$ in that case. In addition, effect of some parameters like fracture permeability, matrix permeability and length of the horizontal wells were studied. Applicability of two most promising thermal techniques namely CSS and SAGD were studied by Das (2007). He performed several simulation analysis Using STARS module of Computer Modeling Group (CMG) software to investigate the effect of different parameters such as oil viscosity, fracture spacing, capillary pressure, wettability and matrix permeability on these two processes. Results demonstrated that better recovery of oil was obtained for SAGD in the case of higher oil viscosity whereas CSS showed better performance in reservoirs with lower viscous oil. Also he mentioned that oil expulsion from matrix and spontaneous water imbibitions are the two key mechanisms for the success of thermal processes.

Mollaei (2007) briefly presented a review of performed researches on the effect of important parameters on application of steam flooding in naturally fractured reservoirs (NFR). The effect of temperature on physical properties of rock and fluids such as viscosity, density, porosity and permeability was investigated. Moreover, effective parameters on two important oil recovery mechanisms in NFRs, namely oil expulsion from matrix to the fracture and oil displacement through the fracture networks, were introduced. Bagci (2007) performed comparative simulation study on SAGD and Steam-Alternating-Solvent (SAS) processes in fractured reservoirs 
under different injection schedules, bottom-hole pressures and fracture orientations. He concluded that SAS process showed better performance than SAGD, however, the proper rate of solvent injection is required. Maintaining the reservoir temperature is important in the SAS process while solvent is injected inside the reservoir. Fracture orientation had no effect on oil production for the various injection schedules.

In order to investigate the effect of fracture orientations on SAGD process, Chen et al. (2007) carried out several simulations. They found that average oil production rate in a model with vertical fractures was more than twice that in a model with horizontal fractures. Edmunds et al. (2009) comprehensively reviewed geological and engineering aspects of historical and current data of bitumen recovery from the Grosmont formation in Alberta. They found that presence of fractures and vugs provided a noteworthy combination of porosity, thickness and oil saturation for steam recovery. A new method called Steam-Over-Solvent has been applied to the fractured reservoirs by Al Bahlani and Babadagli (2009). They carried out series of laboratory experiments and then developed dimensionless parameters to upscale the lab data to the field data. They observed three phases namely fracture oil depletion phase, diffusion dominant and dispersion dominant phases during solvent injection period. The experimental data and simulation results indicated that this technique was successful and promising in the lab and field conditions.

Rezaei et al. (2010) performed some experiments to investigate bitumen recovery from vuggy porous media using VAPEX process. They found the same results as the previous works. Souraki et al. (2011) performed simulation study using Athabasca bitumen PVT experimental data on a core sample surrounded by fractures. They concluded that higher CSOR and faster oil recovery can be obtained for higher injection rates; however, the optimum steam injection rate should be obtained to have economic CSOR. They evaluated the effect of fracture permeability for different steam injection rates and results revealed that higher fracture permeability may be effective in lower rates of injection. The feasibility of Toe-to-Heel Air Injection (THAI) technique in Iranian fractured heavy oil reservoirs was investigated by Fatemi et al. (2011a). They performed experimental work and 3-D simulation study using Kuh-e-Mond oil characteristics. They investigated effect of several parameters such as fracture density, initial oil saturation, horizontal fracture, matrix thickness, matrix permeability and fracture permeability. Higher matrix permeability had positive effect on the process whereas higher fracture permeability reduced the efficiency of the process. Higher oil recovery was achieved for the reservoir with higher fracture density. Moreover, horizontal fractures reduced the ultimate oil recovery.

Fatemi et al. (2011b) investigated the geometrical properties of fractured systems such as discontinuity, length and orientation of fracture by simulating the SAGD process. Simulation results indicated positive and negative effects on oil production for vertical and horizontal fractures respectively. Longer vertical fractures increased oil recovery whereas longer horizontal ones decreased it. In terms of oil recovery, discontinuity displayed damping behavior on performance of both vertical and horizontal fractures. An experimental work on recovery of bitumen from fractured carbonates using hot-solvents was carried out by Pathak and Babadagli (2012). They prepared three original cores with original fluid saturations and tested them in three experiments using different solvents and different pressures and temperatures. They found that the dilution attained by butane was substantially greater than the dilution attained by propane. However, the experimental results revealed that using hot-solvent is a prosperous technique for producing bitumen from complex carbonate rocks.

Based on the aforementioned researches, mostly VAPEX and hot-solvent processes investigated by simulation study or experimental work in fractured reservoirs. Although some simulations and laboratory experiments have been performed on SAGD process but ES-SAGD process which is one of the most promising processes of heavy oil and bitumen recovery has not been conducted in NFRs so much. This process can improve the SAGD performance because it is benefiting from synergy of steam and solvent to reduce the high viscosity of bitumen crudes. In fact, vapor of solvent co-injected into the reservoir with steam. Steam and solvent in vapor phase contact cold bitumen and condense. Condensed solvent diffuses inside the oil and makes it lighter in the boundary of steam chamber. Afterwards, condensations of solvent and steam together with diluted oil are extracted from horizontal producer. Results of simulation studies on sandstone reservoirs revealed that ES-SAGD yield lower cumulative energy consumption and green-house-gas emissions (GHG) than SAGD process. Further, oil production rate, ultimate oil recovery and cumulative steam-oil ratio (CSOR) are significantly improved (Nasr \& Ayodele, 2006). The main objective of this work was to investigate the feasibility of SAGD and ES-SAGD processes in naturally fractured heavy oil reservoirs. Sensitivity analysis has been done on the effect of geological and operational parameters such as fracture spacing, matrix permeability, fracture permeability, reservoir thickness, initial oil viscosity and steam quality. The results of this work have been described in details and demonstrated in related graphs. 


\section{Simulation Studies}

In order to study the applicability of thermal processes in heavy oil naturally fractured reservoirs, several field-scale simulation models were built using STARS module of Computer Modeling Group software (CMG). Two thermal processes namely Steam-Assisted Gravity Drainage (SAGD) and Expanding-Solvent SAGD (ES-SAGD) were studied here. These two methods are the most promising methods in heavy oil and bitumen reservoirs. Athabasca bitumen was used as a fluid in these simulation studies. Some experimental properties of Athabasca bitumen measured in previous works by the authors were applied.

\subsection{Model Description for SAGD Process}

In this work a two dimensional model consisting of $51 \times 1 \times 17$ grid blocks was built to represent a naturally fractured reservoir. The reservoir has dimensions of $306 \mathrm{ft}(93 \mathrm{~m})$ in length, $328 \mathrm{ft}(100 \mathrm{~m})$ in width and a thickness of $51 \mathrm{ft}(15.5 \mathrm{~m})$. Since SAGD process is symmetric, half of the reservoir was simulated. Dual permeability option was applied in all simulation runs, this indicates that in addition to the matrix to fracture fluid flow and inter-block fracture to fracture flows (convection and conduction) inter-block matrix to matrix flows were also accounted for and calculated. Identical fracture spacing of 1 foot in all directions was considered for the base model. The fracture network has permeability of 5 Darcies in each part of the reservoir whereas matrix system has permeability ratio of 0.04 to the fracture network $(0.2 \mathrm{D})$. Matrix and fracture porosities are 0.3 and 0.02 respectively. Two horizontal wells were positioned with $15 \mathrm{ft}(4.57 \mathrm{~m})$ vertical distance at the bottom of the reservoir. The upper well is considered as injector whereas the lower well is acting as producer and located $1.5 \mathrm{ft}$ above the base of model. Both wells were drilled horizontally through the whole J-direction of the model. Figure 1 shows the schematic view of simulation model. Additional information about rock-fluid, fluid properties and heat loss parameters are presented in Table 1. Figures 2 and 3 are presenting the matrix relative permeability curves and viscosity of bitumen which was obtained experimentally in previous works by Ashrafi et al. (2011). The internal liquid viscosity correlation for selected normal alkanes presented in STARS manual was used for the viscosities of the solvents used in ES-SAGD process simulations. This correlation is as follows (CMG-STARS user's guide, 2012):

$$
V I S C=A V I S C \times \exp (B V I S C / T)
$$

Where values of the coefficients $A V I S C$ and $B V I S C$ are given for selected components in STARS manual, VISC is viscosity and $T$ is absolute temperature. Relative permeabilities of fracture network were considered as straight lines. This connotes that the fracture network is almost equivalent to a bundle of tubes where the residual oil and irreducible water saturations are equal to zero (Aguilera, 1995).

Table 1. Reservoir simulation input parameters

\begin{tabular}{ll}
\hline Item & Value \\
\hline Initial oil saturation in matrix system & 0.80 \\
Initial oil saturation in fracture network & 0.05 \\
Rock thermal conductivity, $\mathrm{Btu} /\left(\mathrm{ft}^{*} \mathrm{day}^{* \circ} \mathrm{F}\right)$ & 106 \\
Rock heat capacity, $\mathrm{Btu} /\left(\mathrm{ft}^{3 * \circ} \mathrm{F}\right)(\mathrm{CMG}, 2012)$ & 35 \\
Density of bitumen, $\mathrm{lb} / \mathrm{ft}^{3}$ & 63.26 \\
Molecular weight of bitumen, lb/lbmole & 534 \\
Rock compressibility, $1 / \mathrm{psi}$ & $1.4 \mathrm{E}-5$ \\
Three phase relative permeability model $(\mathrm{CMG}, 2012)$ & Stone's model 2 \\
Initial reservoir temperature, ${ }^{\circ} \mathrm{F}$ & 50 \\
Initial reservoir pressure at the top of the reservoir, psi & 400 \\
Over/under burden heat capacity, Btu/(ft $\left.{ }^{3 *} \mathrm{~F}\right)(\mathrm{CMG}, 2012)$ & 35 \\
Over/under burden thermal conductivity, Btu/(ft*day**o $\mathrm{F})$ & 24 \\
Reservoir has no gas cap and aquifer & \\
\hline
\end{tabular}




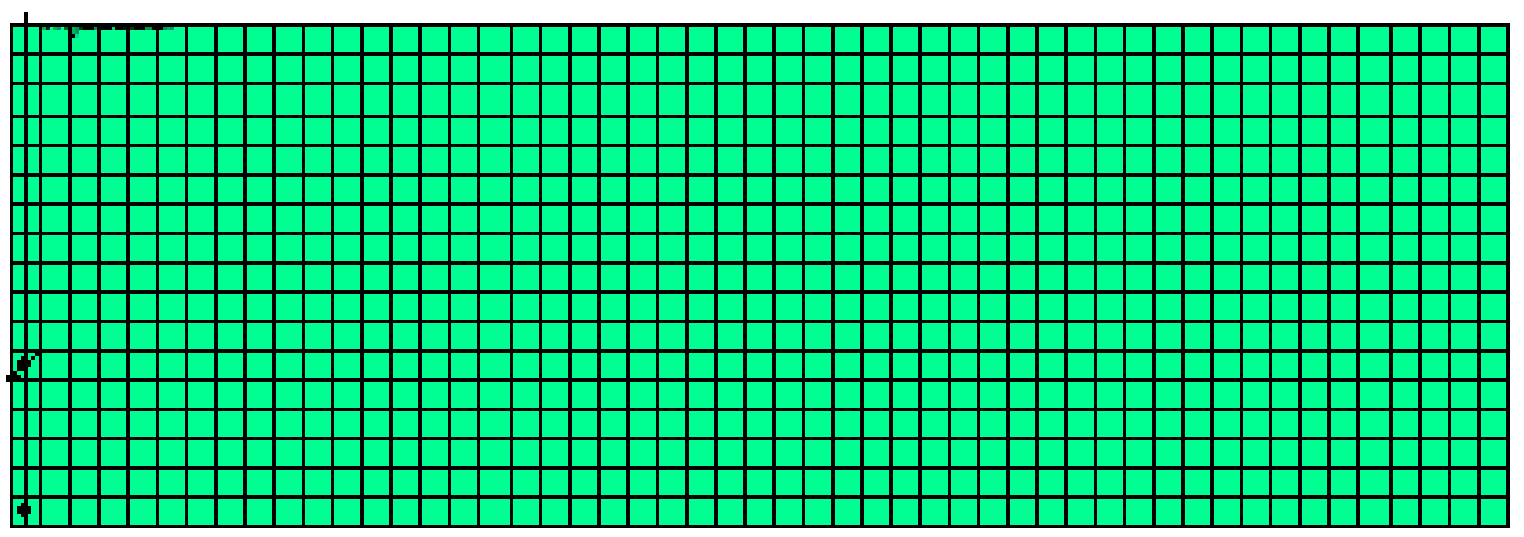

a) Well positions in the simulation model (I-K view)

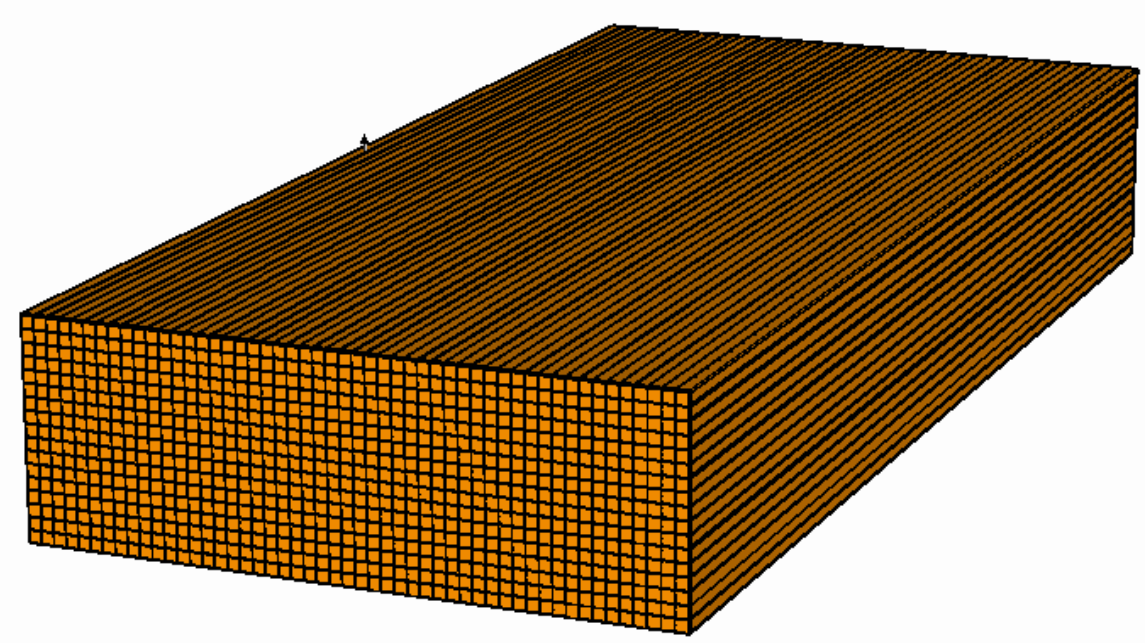

b) 3-D schematic of the simulation model

Figure 1. Reservoir simulation model
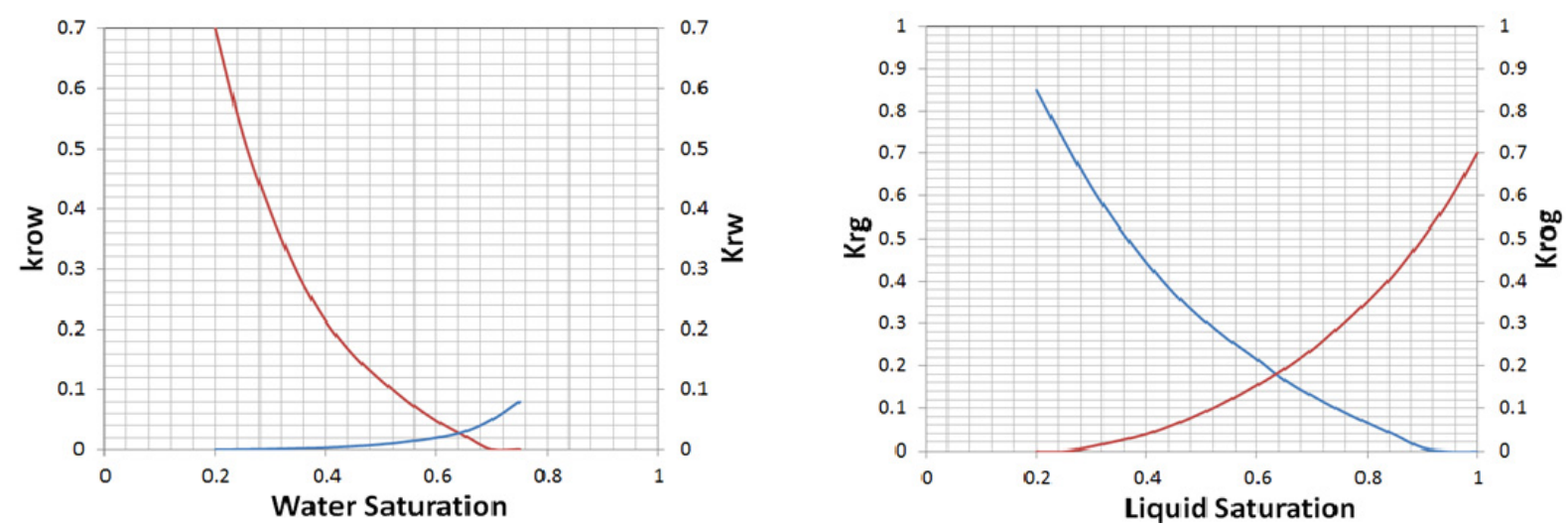

Figure 2. Sketch of the matrix relative permeability data (Chen, 2006) 


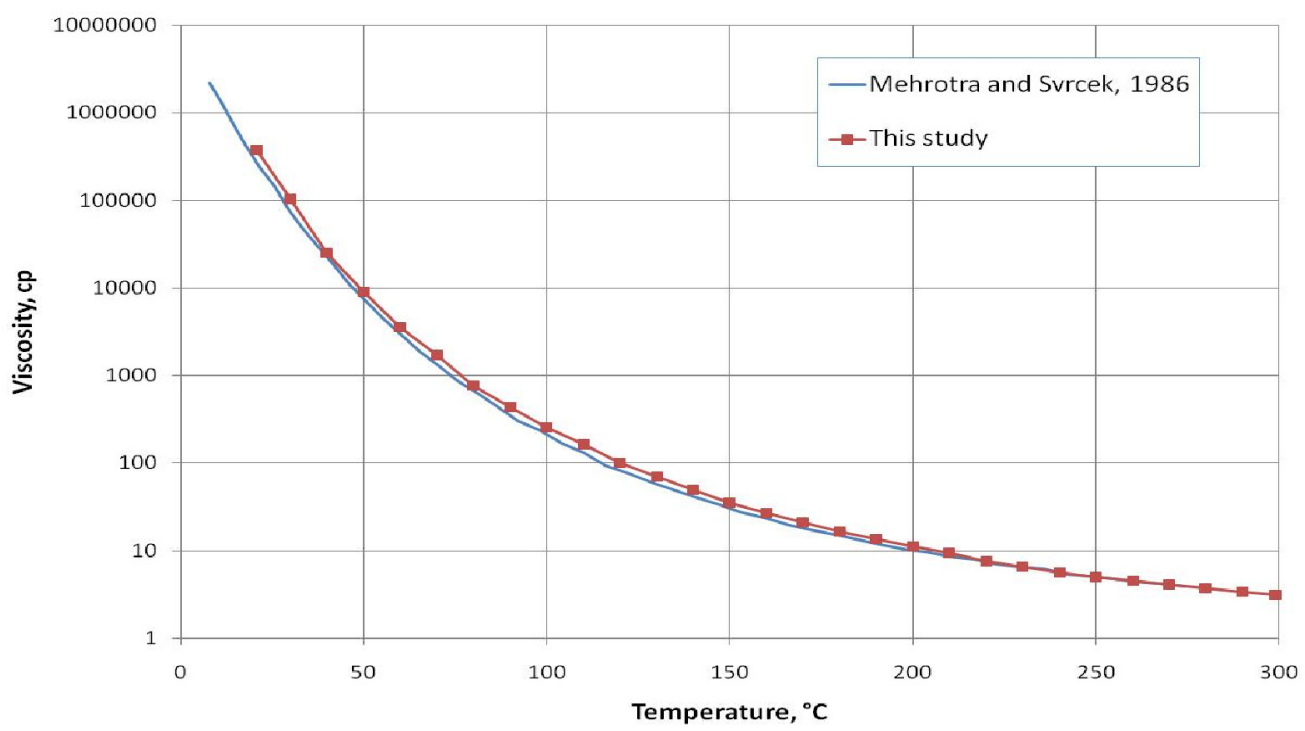

Figure 3. Viscosity of Athabasca bitumen versus temperature (Ashrafi et al., 2011)

Due to the high viscosity of bitumen at the reservoir conditions it is not possible to produce it by pressure depletion which is a primary production method in conventional oil reservoirs. Hence, the reservoir should be heated up to the extent that bitumen becomes mobile. In the SAGD process, in order to establish a good communication between injector and producer, steam is circulated through both horizontal wells or electrical heaters are used to transfer heat to the layers between wells before starting the operation. In this work, electrical heaters were applied to prepare the reservoir for operation. The set temperature of heaters was $500{ }^{\circ} \mathrm{F}$ and it was done for 80 days when the average temperature of layers between the two wells reached to $302{ }^{\circ} \mathrm{F}\left(150{ }^{\circ} \mathrm{C}\right)$. Afterwards, the electrical heaters were turned off. Minimum bottom-hole pressure of 100 psi was applied to the production well as a primary constraint. In addition, steam trap control option was used and set to $20^{\circ} \mathrm{F}$ to hinder the steam production. Steam with quality of $70 \%$, temperature of $490^{\circ} \mathrm{F}$ and maximum injection rate of 400 $\mathrm{STB} /$ day was injected. The maximum bottom-hole pressure of $600 \mathrm{psi}$ was imposed to injection well as a secondary constraint. Both wells have no skin factor.

\subsection{Model Description for ES-SAGD Process}

The same parameters were applied in this process except the steam injection constraint. Here $1 \%$ molar based of hexane was co-injected with steam. Co-injection was performed under the temperature of $490^{\circ} \mathrm{F}$ and steam quality of $70 \%$. The maximum fluid injection rate of $400 \mathrm{STB} /$ day and bottom-hole pressure of 600 psi were imposed to the injection well as constraints. The ES-SAGD process benefits from advantages of steam and solvent together in bitumen's viscosity reduction. Steam conducts heat to the reservoir contains and therefore reduces the oil viscosity but solubility of solvent into the bitumen around the edges of steam chamber results in viscosity reduction of oil. Solubility of the solvents in bitumen is reflected in K-values of the solvents. K-values are the ratios of the mole fraction of each solvent in vapor phase to that in liquid phase at thermodynamic equilibrium condition. K-values are therefore temperature, pressure and concentration dependant. In this study the K-values of the solvents versus temperature and pressure were estimated using the following equation provided in STARS manual (CMG-STARS user's guide, 2012):

$$
K=(K V 1 / P) \times \exp (K V 4 /(T-K V 5))
$$

Where coefficients $K V 1, K V 4$ and $K V 5$ are component dependant and presented in STARS manual for selected components. $P$ and $T$ are pressure and absolute temperature respectively.

Table 2. K-value coefficients of selected solvents

\begin{tabular}{llll}
\hline K-value coefficients & n-pentane & n-hexane & n-heptane \\
\hline$K V 1(\mathrm{psi})$ & $1.4546 \mathrm{e}+5$ & $1.4594 \mathrm{e}+5$ & $1.5145 \mathrm{e}+5$ \\
$K V 4\left({ }^{\circ} \mathrm{F}\right)$ & -4458.73 & -4855.59 & -5240.38 \\
$K V 5\left({ }^{\circ} \mathrm{F}\right)$ & -387.78 & -371.87 & -357.95 \\
\hline
\end{tabular}




\section{Results and Discussion}

\subsection{SAGD vs. ES-SAGD}

Simulation results demonstrated that both processes in this work are efficient and practically applicable. However, ES-SAGD had a better performance from economical point of view. The most important economical parameters are recovery factor and cumulative steam-oil ratio (CSOR). Figure 4a illustrates that ultimate recovery factor in SAGD case is about 64 percent after 4400 days (12 years) which is economically acceptable whereas ES-SAGD shows a very promising recovery factor of 90 percent just after 2000 days (5.5 years). It should be noted that this is a net recovery factor, i.e., produced solvent has been deducted from total oil production. Considering CSOR, figure $4 \mathrm{~b}$ remarks that ES-SAGD can be applied with a reasonable CSOR of 4 $\mathrm{bbl} / \mathrm{bbl}$. However, SAGD performance was inside the economical border of CSOR in the field conditions. Average oil production rate of 50 and $100 \mathrm{bbl} /$ day were obtained up to 2000 days of production for SAGD and ES-SAGD processes respectively (Figure 4c). In order to generate steam, energy is required. Energy will be lost inside the reservoir via over/under burden. Figure $4 \mathrm{~d}$ illustrates that energy lost to over/under burden is lower in ES-SAGD process than in the SAGD process.

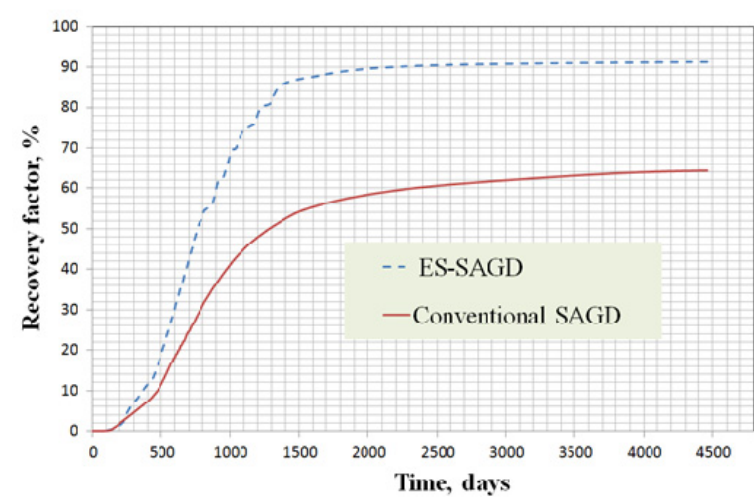

a) Recovery factor vs. time

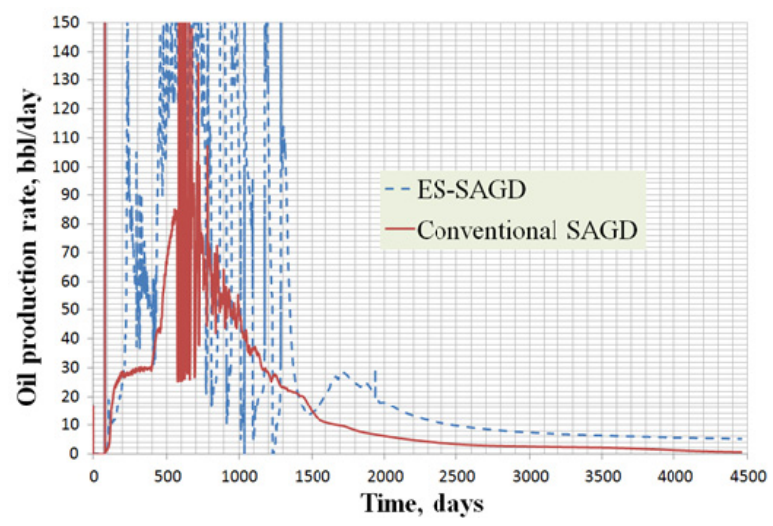

c) Oil production rate vs. time

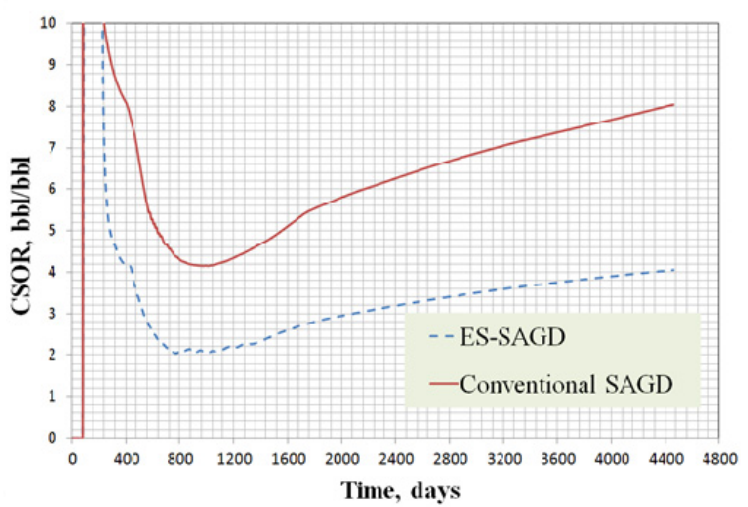

b) CSOR vs. time

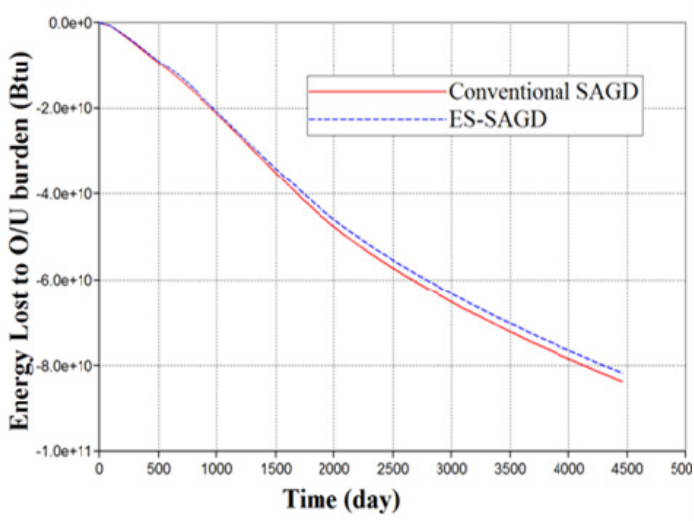

d) Energy lost to over/under burden vs. time

Figure 4. Illustration of SAGD and ES-SAGD performance comparison

Solvents are expensive; hence, injecting solvent into the reservoir should be evaluated economically. However, it is possible to recover most of the injected solvents as heavy oil and bitumen are upgraded at the surface. In SAGD process produced oil will be upgraded by adding solvent at surface and then transferred to the refinery. In fact, ES-SAGD is a method to upgrade heavy oil inside the reservoir. Figure 5 shows the injected and produced amount of hexane as solvent in this study. During production time $40914 \mathrm{bbls}$ of hexane injected and $39029 \mathrm{bbls}$ produced. In fact, only 1885 bbls of hexane remained inside the reservoir which is less than $5 \%$ of injected solvent volume. 


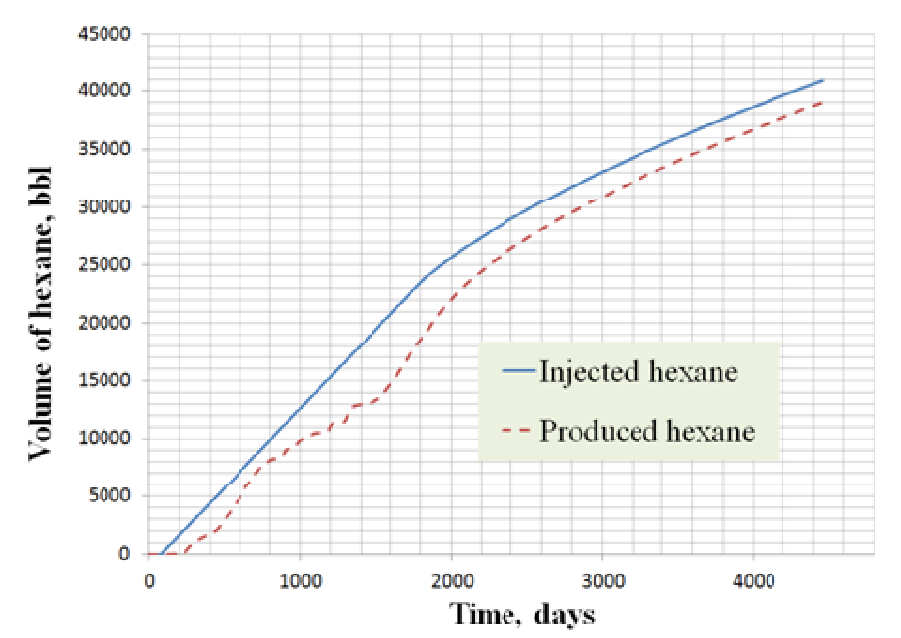

Figure 5. Illustration of injected and produced volume of hexane vs. time

\subsection{Effect of Fracture Spacing}

Impact of fracture spacing on SAGD and ES-SAGD processes was studied. The base case had fracture spacing of 1 foot and it was changed to $2 \mathrm{ft}$ for deliberating the results. The results show that fracture spacing has no significant effect on recovery factor and CSOR in SAGD process. Larger fracture spacing resulted in higher oil recovery factor in ES-SAGD process and lower amount of CSOR in earlier period of production (Figure 6).
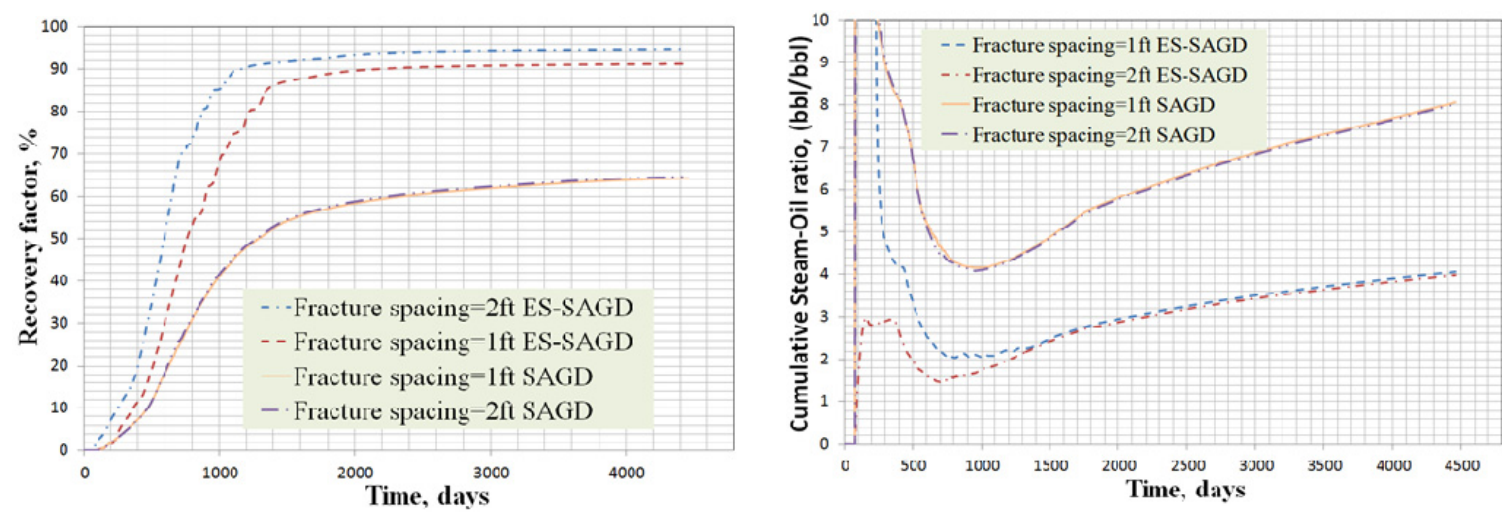

Figure 6. Illustration of the effect of fracture spacing

\subsection{Reservoir Thickness}

Conventional reservoirs with higher thickness are more suitable for conventional SAGD process as lower amount of steam will be lost due to the over/under burden. Hence, in this part of the study we tried to investigate the effect of reservoir thickness on SAGD performance in naturally fractured reservoirs. Reservoir thickness was increased to $81 \mathrm{ft}(24.7 \mathrm{~m})$, moreover production well was located $1.5 \mathrm{ft}$ above the base of the reservoir and injector was placed at a vertical distance of $15 \mathrm{ft}$ from producer. The other parameters and constraints were kept the same as before. Since the rate of injection was equal for all cases, the ultimate recovery factor was identical. However, reservoir with larger thickness has weaker performance at earlier period of production. It means that there is possibility to increase rate of injection as it can be seen based on the CSOR curves. Therefore, higher thickness can improve the performance of thermal processes such as conventional SAGD and ES-SAGD even in naturally fractured reservoirs. Figure 7 illustrates the reservoir thickness effects. 

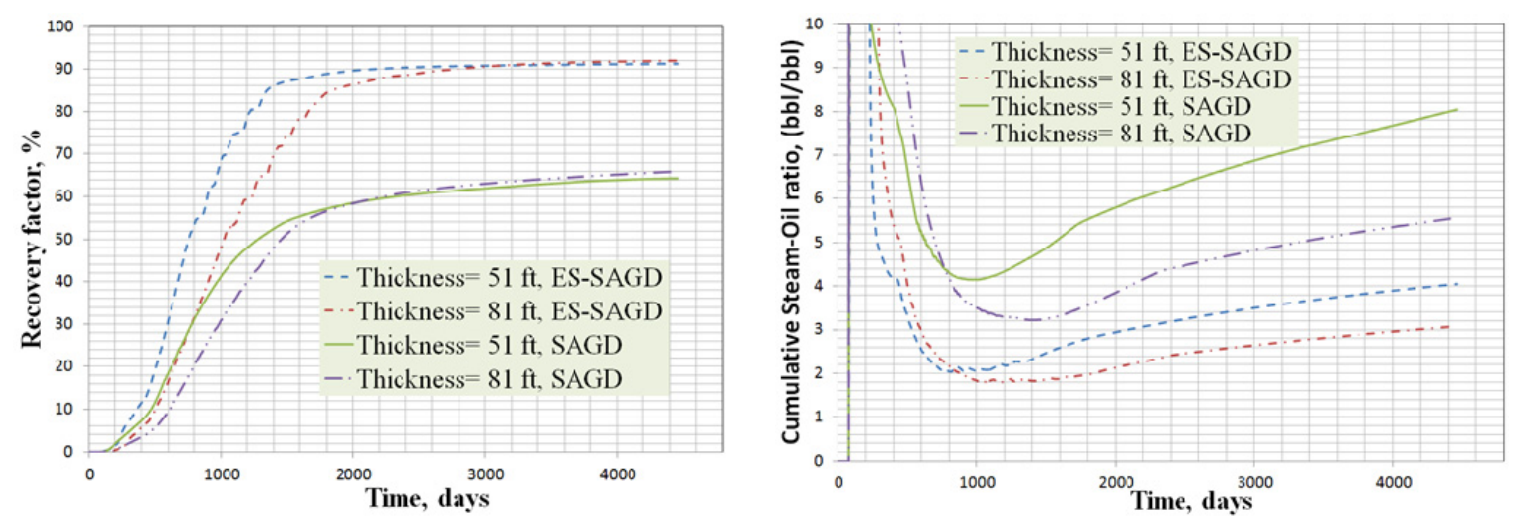

Figure 7. Illustration of the effect of reservoir thickness

\subsection{Oil Viscosity}

Athabasca bitumen properties were used for base cases simulations of SAGD and ES-SAGD processes. To investigate impacts of in-situ oil viscosity, Lloydminster oil properties were applied. Viscosities of these two types of heavy oils versus temperature are depicted in Figure 8.

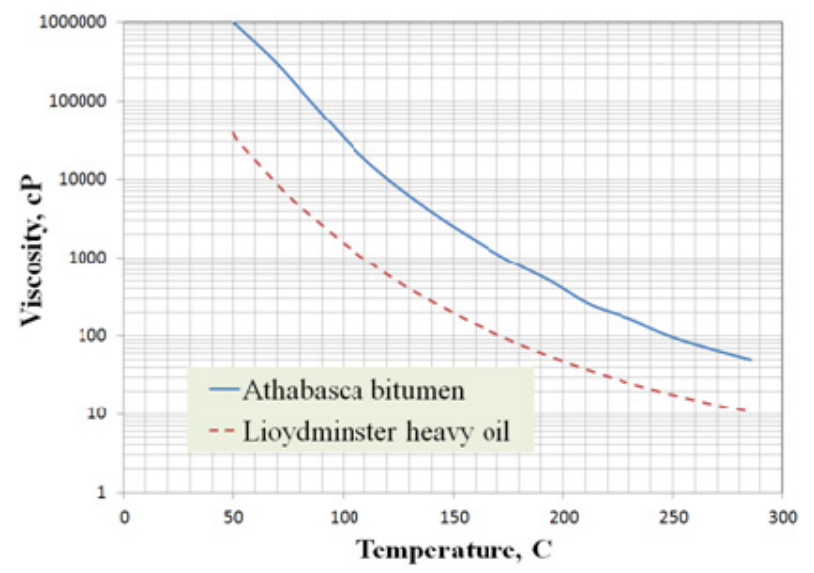

Figure 8. Illustration of different heavy oil viscosities vs. time
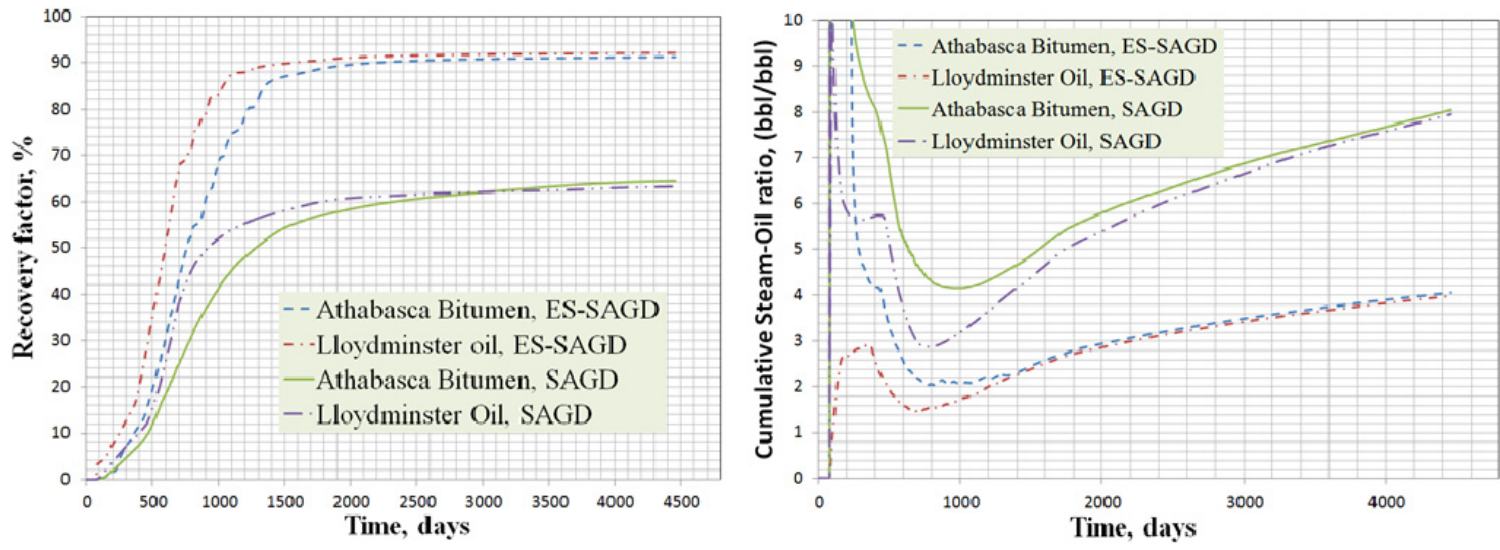

Figure 9. Illustration of the oil viscosity effect

The ultimate recovery factor of both processes for the aforementioned types of oils are almost the same, faster oil production was observed in the case of lighter oil. Hence, lighter oil will be mobile in lower temperatures and 
can be produced earlier than the heavier oil. This results in lower CSOR for earlier periods of production. When the reservoir matures both kinds of oil can be produced, thus the ultimate recovery is almost the same. Figure 9 displays the effect of oil viscosity.

\subsection{Fracture Permeability}

Evaluation of fracture permeability was performed by changing it from 5 Darcies to 10 Darcies. Figure 10 demonstrates that faster and higher recovery has been obtained for higher fracture permeability model even in SAGD process. Fracture transfers drained oil from matrices, so fracture properties govern flow of fluids. Hence, higher permeability of fracture means fluids can be transferred faster and easier. Due to the faster and higher recovery, CSOR will be lower which is more favorable for economy of the operation.
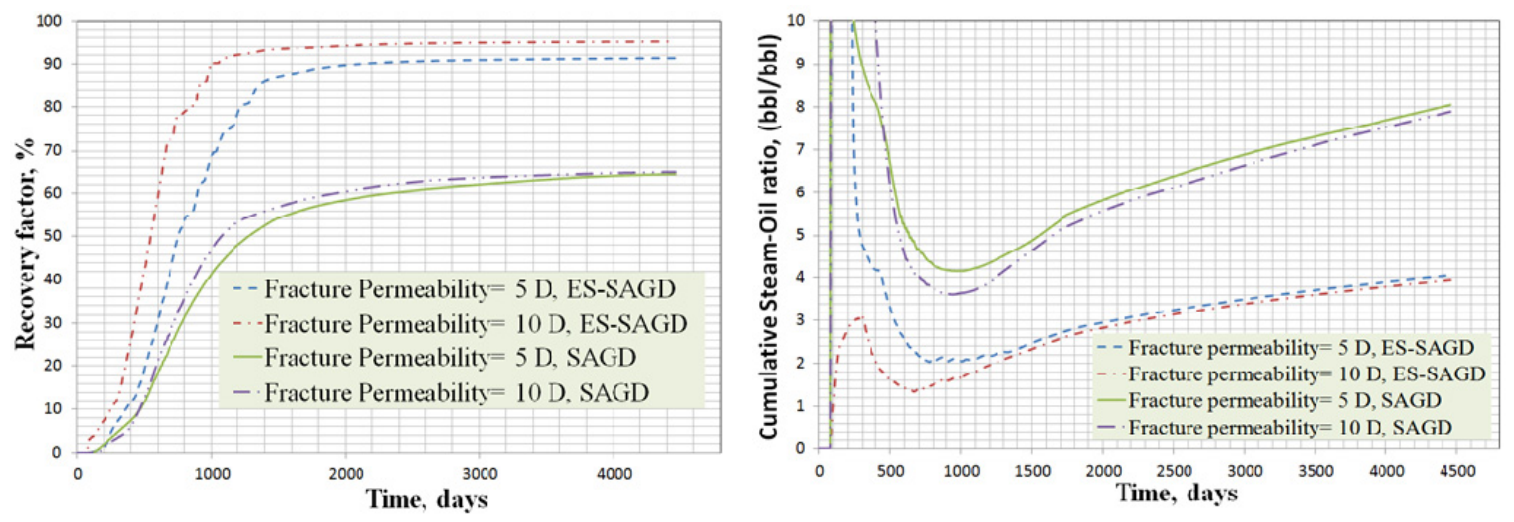

Figure 10. Illustration of the effect of fracture permeability

\subsection{Matrix Permeability}

Naturally fractured reservoirs are usually modeled using two different porosity and permeability properties due to matrix system and fracture network. Fracture permeability impacts were studied in the previous section. In this part, matrix permeability effects are evaluated. For this purpose permeability of matrix system was increased from 0.2 to 0.5 Darcies. Figure 11 shows that higher matrix permeability has significant effect on recovery factor and CSOR. In fact, higher matrix permeability resulted in faster and higher drainage of oil from matrices to the fractures and therefore improvement in oil recovery and CSOR and eventually the economy of the process.
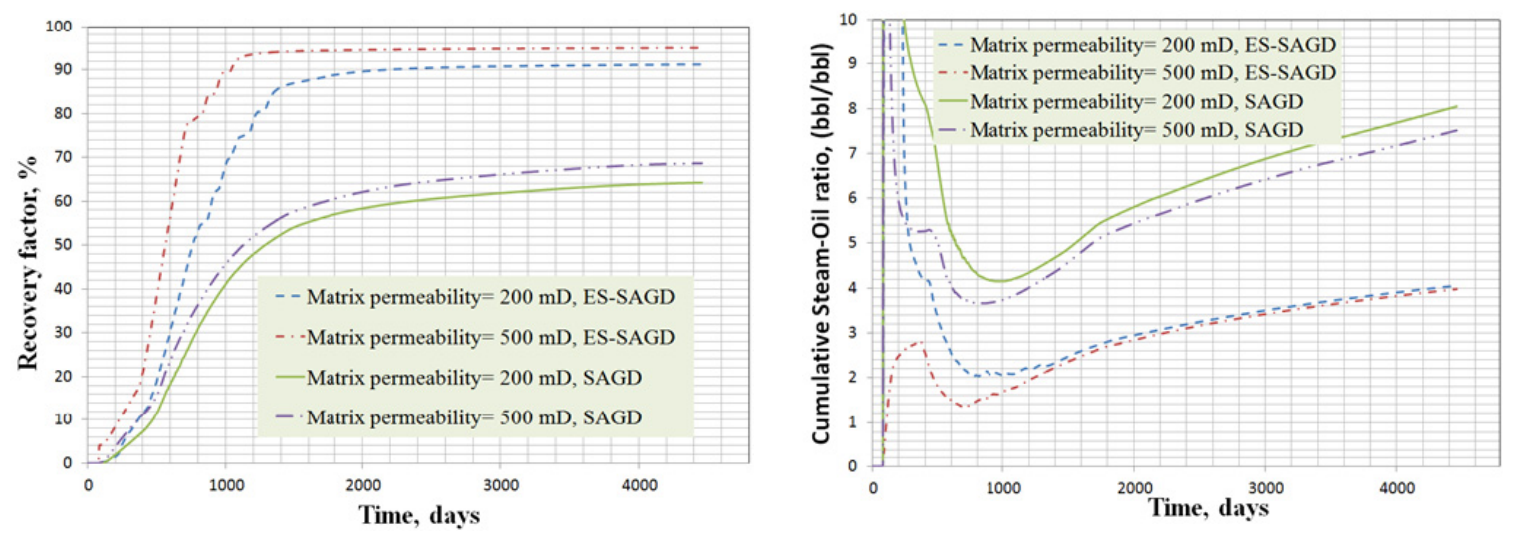

Figure 11. Illustration of matrix permeability impact 


\subsection{Steam Quality}

In the field conditions it is impossible to have dry steam inside the reservoir due to the heat losses from surface to the reservoir inside the casing and liner. Two different steam qualities of 0.7 and 0.85 were studied in this work. Simulation results illustrated that faster recovery of oil can be obtained if steam has higher quality inside the reservoir (Figure 12). Obviously, steam has more heat capacity than water due to its latent heat. If steam has higher quality inside the reservoir, more heat content and energy can be transferred to the reservoir. It seems that steam quality effects are more pronounced in case of SAGD process where there is only steam injected to reduce the viscosity of heavy oil.
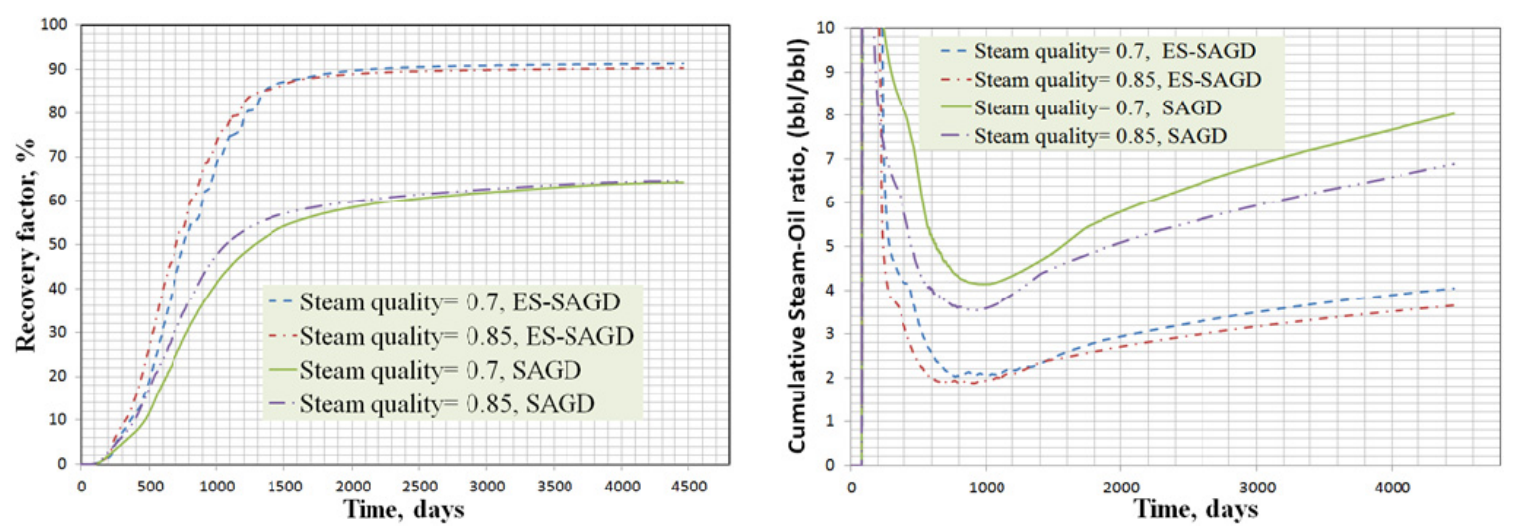

Figure 12. Illustration of steam quality effect

\subsection{Solvent Type Effect}

In order to find out the effective parameters on ES-SAGD process, solvent type effects were studied in this section. For this purpose, three different solvent types namely pentane, hexane and heptane were selected. They were injected with same mole percent of 1 in to the reservoir. Figure 13 illustrates the results of simulation studies for different types of solvents.
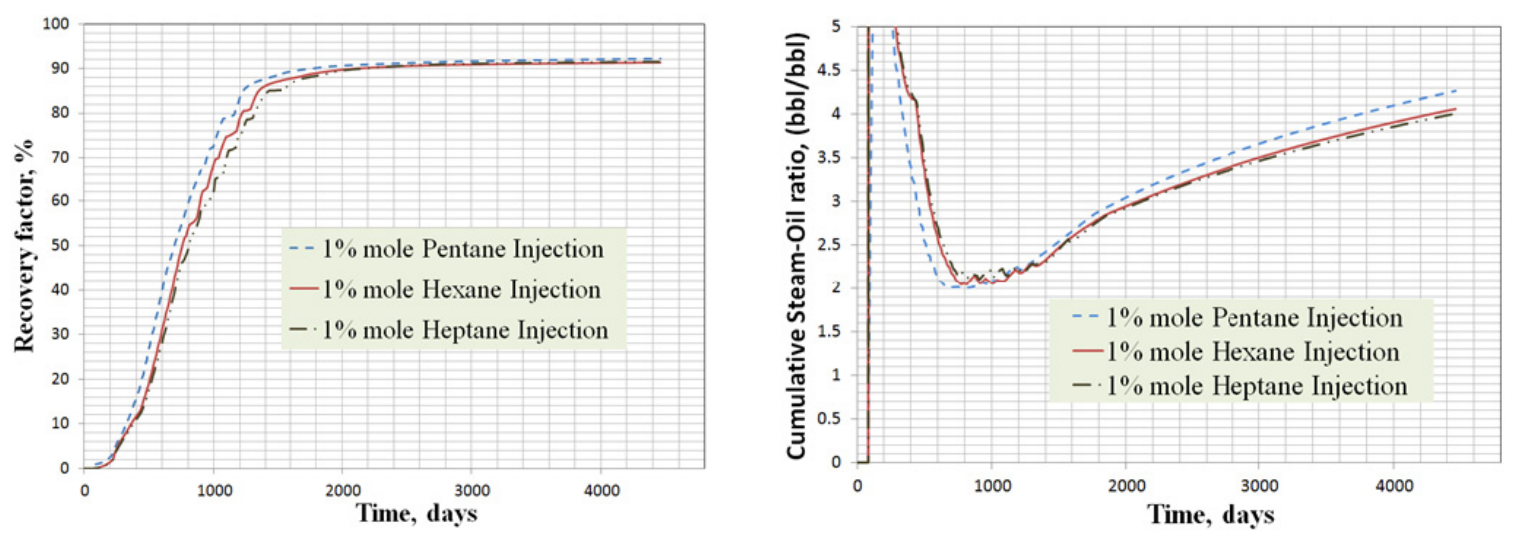

Figure 13. Illustration of the effect of solvent type

Figure 14 compares the net injected energy for each solvent until 1800 days of production. Pentane had a better performance than the others, because more energy was injected in this case. Obviously lighter solvent has lower volume based on the same mole fraction. Hence, more steam will be injected in lighter solvent case, and because steam has the main role in the mitigation of oil viscosity, higher recovery factor can be obtained. Considering CSOR it can be seen that more steam was injected in lighter solvent case which was pentane in this work. However, at later period of production heavier solvents had better performance based on CSOR. 


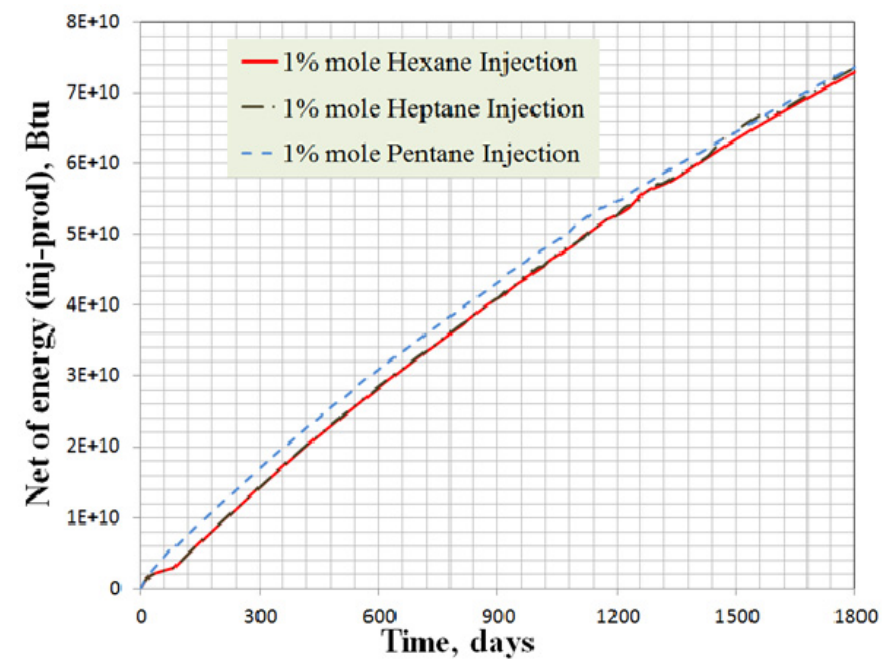

Figure 14. Comparison of net injected energy for different solvent types

\subsection{Effect of Solvent Concentration}

In the ES-SAGD process solvent concentration was increased to 2 mole percent in order to investigate solvent concentration effects. Results displayed significant impacts on recovery factor and CSOR. With only 1 mole percent increase in solvent concentration recovery factor increased from $91 \%$ to $95 \%$ and CSOR improved from 4 to $3.1 \mathrm{bbl} / \mathrm{bbl}$ (Figure 15). Clearly higher solvent injection can help the process to reduce the viscosity of heavy oil and bitumen but it should be noted that steam has main role in ES-SAGD process as it can reduce viscosity faster than solvent. Solvent is expensive, so it is very important to find the optimum solvent concentration for each ES-SAGD operation based on the reservoir conditions.
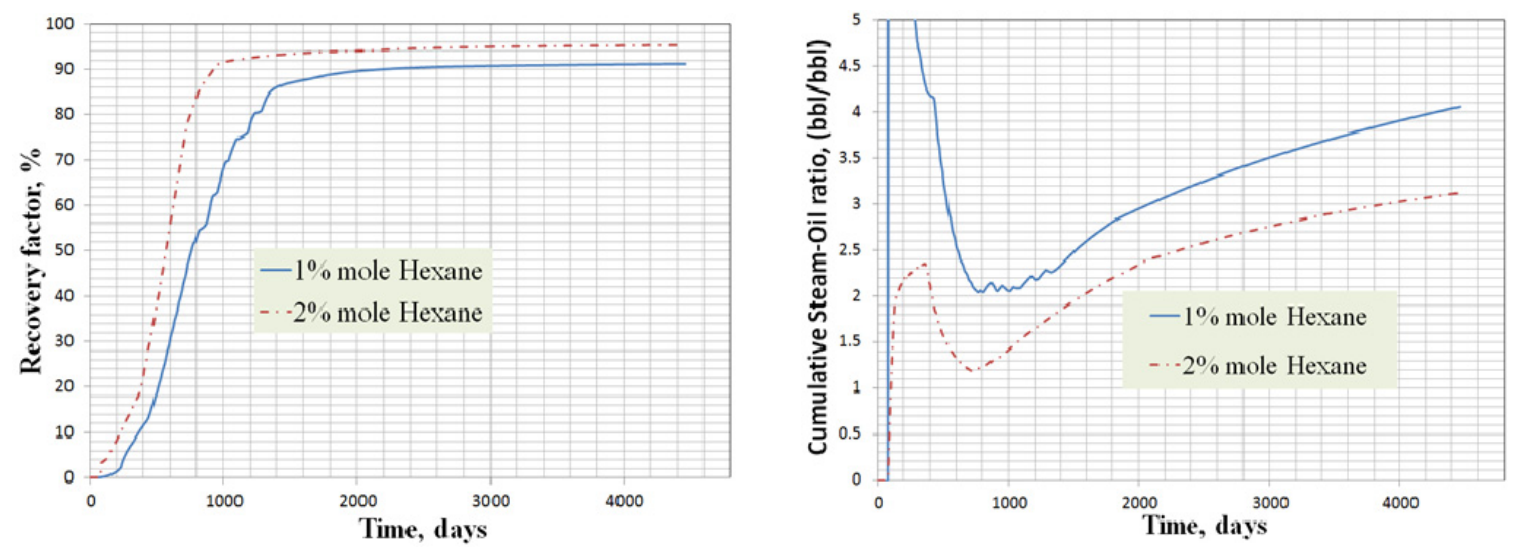

Figure 15. Illustration of solvent concentration effects

\section{Conclusion}

The results of this study showed that SAGD and ES-SAGD are feasible techniques to recover bitumen and heavy oil from naturally fractured reservoirs. ES-SAGD displayed extremely prosperous performance resulting in lower amount of CSOR and higher recovery than SAGD. Wider fracture spacing had no effect on SAGD process while faster recovery was obtained in the ES-SAGD process. Thicker reservoirs provide better conditions for thermal processes such as SAGD and ES-SAGD. Initial oil viscosity and steam quality can affect the mentioned processes. In fact, lower initial oil viscosity and higher steam quality can help the processes to be faster in the early periods of production. SAGD performance was more sensitive to the changes in the permeability of matrix than fracture. However, ES-SAGD was affected by changes in both the matrix and fracture permeabilities. Since solvents are expensive oil products, the type and optimum concentration of injected solvent should be chosen based on thorough study of the reservoir properties and operational conditions. High consumption of energy and 
water plus emission of green-house-gases like $\mathrm{CO}_{2}$ are the main deficiencies of SAGD process, while ES-SAGD can yield higher recovery by using lower amount of water and energy. Another advantage of this process is lower amount of green-house-gas emission which is important from environmental point of view.

\section{Acknowledgment}

The authors would like to thank Statoil ASA for financial supports. We are also thankful to CMG Ltd. for providing us the license to STARS software.

\section{References}

Aguilera, R. (1995). Naturally fractured reservoirs (2nd ed.). Tulsa, Oklahoma: Penn Well Books.

Al Bahlani, \& Babadagli, T. (2009). Laboratory and Field Scale Analysis of Steam Over Solvent Injection in Fractured Reservoirs (SOS-FR) for Heavy-Oil Recovery. Paper SPE 124047 presented at the 2009 SPE Annual Technical Conference and Exhibition held in New Orleans, Louisiana, USA, 4-7 October.

Ashrafi, M., Souraki, Y., Karimaie, H., Torsaeter, O., \& Bjorkvik, B. J. A. (2011). Experimental PVT Property Analyses for Athabasca Bitumen. Paper CSUG/SPE 147064 presented at the Canadian Unconventional Resources Conference held in Calgary, Alberta, Canada, 15-17 November. http://dx.doi.org/10.2118/147064-MS

Azin, R., Kharrat, R., Ghotbi, C., \& Vossoughi, S. (2005). Applicability of the VAPEX Process to Iranian Heavy Oil Reservoirs. Paper SPE 92720 presented at the 14th SPE Middle East Oil \& Gas Show and Conference held in Bahrain International Exhibition Center, Bahrain, 12-15 March. http://dx.doi.org/10.2118/92720-MS

Bagci, A. S. (2006). Experimental and Simulation Studies of SAGD Process in Fractured Reservoirs. Paper SPE 99920 presented at the 2006 SPE/DOE Symposium on Improved Oil Recovery held in Tulsa, Oklahoma, U.S.A., 22-26 April. http://dx.doi.org/10.2118/99920-MS

Bagci, A. S., Samuel, O. M., \& Mackay, M. (2007). Paper 2007-040 presented at the Petroleum Society's 8th Canadian International Petroleum Conference (58th Annual Technical Meeting) held in Calgary, Alberta, Canada, 12-14 June. http://dx.doi.org/10.2118/2007-040

Butler, R. M., \& Jiang, Q. (2000). Improved Recovery of Heavy Oil by VAPEX with Widely Spaced Horizontal Injectors and Producers. JCPT, 39(1), 48-56. http://dx.doi.org/10.2118/00-01-04

Chen, Q. (2006). Assessing and Improving Steam-Assisted Gravity Drainage: Reservoir Heterogeneities, Hydraulic Fractures and Mobility Control Foam, Dissertation for Doctor of Philosophy Degree, Stanford University, USA. Retrieved from http://pangea.stanford.edu/ERE/pdf/pereports/PhD/ChenQing09.pdf

Chen, Q., Gerritsen, M. G., \& Kovscek, A. R. (2007). Paper SPE 109873 presented at the 2007 SPE Annual Technical Conference and Exhibition held in Anaheim, California, USA, 11-14 November. http://dx.doi.org/10.2118/109873-MS

CMG-STARS User's Guide. (2012). Computer Modeling Group Ltd.

Das, S. (2007). Application of Thermal Processes in Heavy Oil Carbonate Reservoirs. Paper SPE 105392 presented at the 15th SPE Middle East Oil \& Gas Show and Conference held in Bahrain International Exhibition Center, Bahrain, 11-14 March. http://dx.doi.org/10.2118/105392-MS

Dusseault, M. B., \& Shafiei, A. (2010). Ullmann's Encyclopedia of Industrial Chemistry, Wiley-VCH. http://dx.doi.org/10.1002/14356007

Edmunds, N., Barrett, K., Solanki, S., Cimolai, M., \& Wong, A. (2009). Prospect for Commercial Bitumen Recovery from the Grosmont Carbonate, Alberta. JCPT, 48(9), 26-32. http://dx.doi.org/10.2118/09-09-26

Fatemi, S. M., Ghotbi, C., Kharrat, R., \& Badakhshan, A. (2011a). Application of Toe-to-Heel Air Injection (THAI) Process in Fractured Carbonate Systems: 3D Simulation of the Effect of Fractures Geometrical properties, Reservoir and Operational Parameters. Paper SPE 143434 presented at the SPE EUROPEC/EAGE Annual Conference and Exhibition held in Vienna, Austria, 23-26 May. http://dx.doi.org/10.2118/143434-MS

Fatemi, S. M., Kharrat, R., \& Vossoughi, S. (2011b). Investigation of Steam Assisted Gravity drainage (SAGD) and Expanding Solvent-SAGD (ES-SAGD) Processes in Complex Fractured Models: Effects of Fractures' Geometrical Properties. Paper SPE 150082 presented at the SPE Heavy Oil Conference and Exhibition held in Kuwait City, Kuwait, 12-14 December. http://dx.doi.org/10.2118/150082-MS

Joshi, S. D. (1986). A Laboratory Study of Thermal Oil recovery Using Horizontal Wells. Paper SPE 14916 
presented at the SPE/DOE Symposium on Enhanced Oil Recovery held in Tulsa, Oklahoma, USA, 20-23 April. http://dx.doi.org/10.2118/14916-MS

Kharrat, R., Vossoughi, S., Azin, R., \& Razzaghi, S. (2003). The Investigation of Using Thermal Methods for Heavy Oil Recovery. Phase I, Internal Document, Petroleum University of Technology, Iran.

Mollaei, A., Maini, B., \& Jalilavi, M. (2007). Investigation of Steam Flooding in Naturally Fractured Reservoirs. Paper presented at the International Petroleum technology Conference held in Dubai, UAE, 4-6 December. http://dx.doi.org/10.2523/11087-MS

Mollaei, A., \& Maini, B. (2010). Steam Flooding of Naturally Fractured Reservoirs: Basic Concepts and Recovery Mechanisms. JCPT, 49(1), 65-70. http://dx.doi.org/10.2118/132485-MS

Nasr, T. N., \& Ayodele, O. R. (2006). New Hybrid Steam-Solvent Processes for the Recovery of Heavy Oil and Bitumen. Paper SPE 101717 presented at the 2006 Abu Dhabi International Petroleum Exhibition and Conference held in Abu Dhabi, UAE, 5-8 November. http://dx.doi.org/10.2118/101717-MS

Pathak, V., \& Babadagli, T. (2012). Experimental Investigation of Bitumen Recovery from Fractured Carbonates Using Hot-Solvents. Paper SPE 159439 presented at the SPE Annual Technical Conference and Exhibition held in San Antonio, Texas, U.S.A., 8-10 October. http://dx.doi.org/10.2118/159439-MS

Pooladi-Darvish, M., \& Farouq, A. (1994). Steam Heating of Fractured Formations Containing Heavy Oil: Basic Premises and a Single-Block Analytical Model. Paper SPE 28642 presented at the SPE 69th Annual Conference and Exhibition held in New Orleans, LA, U.S.A., 25-28 September. http://dx.doi.org/10.2118/28642-MS

Pooladi-Darvish, M., Tortike, W. S., \& Farouq, A. (1995). A New Semi-Analytical Model for Thermal Recovery Processes. Paper SPE 29660 presented at the SPE Western Regional Meeting held in Bakersfield, CA, U.S.A., 8-10 March. http://dx.doi.org/10.2118/29660-MS

Rezaei, N., Mohammadzadeh, O., \& Chatzis, I. (2010). Experimental Investigation of Vapor Extraction Process in the Recovery of Bitumen from Vuggy Porous Media. Paper CSUG/SPE 137829 presented at the Canadian Unconventional Resources \& International Petroleum Conference held in Calgary, Alberta, Canada, 19-21 October. http://dx.doi.org/10.2118/137829-MS

Rostami, B., Azin, R., \& Kharrat, R. (2005). Investigation of the Vapex Process in High-Pressure Fractured Heavy Oil Reservoirs. Paper SPE/PS-CIM/CHOA 97766 presented at the 2005 SPE International Thermal Operations and Heavy Oil Symposium held in Calgary, Alberta, Canada, 1-3 November. http://dx.doi.org/10.2118/97766-MS

Sedaee, S. B., \& Rashidi, F. (2006). Application of the SAGD to an Iranian Carbonate Heavy Oil Reservoir. Paper SPE 100533 presented at the 2006 SPE Western Regional/AAPG Pacific Section/GSA Cordilleran Section Joint Meeting held in Anchorage, Alaska, U.S.A., 8-10 May. http://dx.doi.org/10.2118/100533-MS

Souraki, Y., Ashrafi, M., Karimaie, H., \& Torsaeter, O. (2011). Experimental Investigation and Numerical Simulation of Steam Flooding in Heavy Oil Fractured Reservoir. Paper SPE 144552 presented at the SPE Western North American Regional Meeting held in Anchorage, Alaska, U.S.A., 7-11 May. http://dx.doi.org/10.2118/144552-MS 